Check for updates

Cite this: RSC Adv., 2018, 8, 27537

Received 26th April 2018 Accepted 20th July 2018

DOI: $10.1039 / \mathrm{c} 8 \mathrm{ra0} 6319 \mathrm{e}$

rsc.li/rsc-advances

\title{
Modulating effect of selected pharmaceuticals on bone in female rats exposed to 2,3,7,8- tetrachlorodibenzo-p-dioxin (TCDD)
}

\author{
Maciej Dobrzynski, (D) *a Celina Pezowicz, ${ }^{\mathrm{b}}$ Magdalena Tomanik, ${ }^{\mathrm{b}}$ Piotr Kuropka, ${ }^{\mathrm{c}}$ \\ Krzysztof Dudek, ${ }^{d}$ Katarzyna Fita, ${ }^{a}$ Marzena Styczynska ${ }^{e}$ and Rafal J. Wiglusz (iD *f
}

\begin{abstract}
This paper discusses the problems connected with the influence of TCDD on the mechanical properties and structure of the bone tissue in female rats treated with the dioxin. Moreover an analysis of the protective role of tocopherol, acetylsalicylic acid, dexamethazone and levamisol was performed. Rat tibiae were assessed by mechanical testing, and histological and trace element analysis. It was proved that TCDD has negative effect on bone mechanical properties, histological microstructure and trace element content. The results indicate that usage of both steroid and non-steroid anti-inflammatory medicaments, along with tocopherol and levamisol, modulating their activity, can reduce the negative effect of dioxin activity on the bone tissue of female rats intoxicated with TCDD.
\end{abstract}

\section{Introduction}

Polychlorinated dibenzodioxins and dibenzofurans belong to a large group of chemical substances called dioxins responsible for environmental contamination occurring as a side effect in an array of technological processes as well as during the burning of organic matter. Dioxins are produced in any thermal process under defined conditions, i.e. the presence of chlorine, the burning temperature of $200-900{ }^{\circ} \mathrm{C}$, low oxygenation and presence of water. $^{1-3} \mathrm{~A}$ model dioxin characterized by high toxicity is $2,3,7,8$-tetrachlorodibenzo- $p$-dioxin (TCDD), acknowledged by the International Agency for Research on Cancer (IARC) as a carcinogen representing group A.,

The molecular activity of TCDD and other dioxins is based on activation of the transcription of genes for the enzymes which metabolize xenobiotics, including different molecular forms of cytochrome P-450 (CYP), the family CYP1A1 in particular., ${ }^{\mathbf{1 , 4 6 - 8}}$

${ }^{a}$ Department of Conservative Dentistry and Pedodontics, The Faculty of Dentistry, Wroclaw Medical University, Poland. E-mail: maciej.dobrzynski@umed.wroc.pl; Fax: +48(71)784-03-62; Tel: +48(71)784-03-61

${ }^{b}$ Department of Biomedical Engineering, Mechatronics and Theory of Mechanisms, Faculty of Mechanical Engineering, Wroclaw University of Science and Technology, Poland

${ }^{c}$ Department of Histology and Embryology, Faculty of Veterinary Medicine, Wroclaw University of Environmental and Life Sciences, Poland

${ }^{d}$ Department of Logistics and Transport Systems, Faculty of Mechanical Engineering, Wroclaw University of Science and Technology, Poland

${ }^{e}$ Department of Human Nutrition, Faculty of Food Science, Wroclaw University of Environmental and Life Sciences, Poland

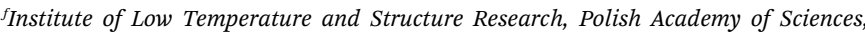
Okolna 2, 50-422 Wroclaw, Poland. E-mail: r.wiglusz@intibs.pl; Fax: +48(71)34410-29; +48(71)395-41-59
In numerous cases the reactions catalyzed by this cytochrome lead to production of toxic metabolites as well as mutagenic intermediate products. ${ }^{7}$ Toxic metabolites and intermediate products affect the expression of genes responsible for the growth and differentiation of cells and also the expression of genes that control biochemical reactions, i.e. synthesis of hormones, enzymes and growth factors. ${ }^{2,8}$

In the case of bone tissue, the osteoblasts synthesize multiple-matrix proteins that undergo mineralization controlled by specific enzymes. The biosynthesis of the matrix proteins mentioned is negatively affected by many xenobiotics, including the TCDD. It can be a reason of bone mineralization disorders. ${ }^{3}$

The promising positive effects by tocopherol on structural and functional prevention of organs in the experimental intoxication by dioxins have prompted the authors to compare well known anti-inflammatory and immunomodulating drugs on bone metabolism. ${ }^{9-13}$ It was shown that administration of tocopherol or acetylsalicylic acid in mothers exposed to TCDD prevent decreases in calcium and magnesium concentrations in the calvaria of the offspring. ${ }^{1}$ Moreover a protective effect of a low dose of $\alpha$-tocopherol on $\mathrm{Mg}$ and Ca level in the bone of rat offspring after intoxicating rat female rats with TCDD before insemination was evidenced. ${ }^{\mathbf{1 4}}$

TCDD, exerting influence on the activity of certain hormones and their receptors (estrogens, corticosterone, T3), can modify the metabolism in bones. ${ }^{\mathbf{1 , 4 1 5 - 1 8}}$ As a result, disturbance of calcium deposition in bones is observed, while the increased concentration of corticosterone in blood stimulates decomposition of collagen fibers. Moreover, by affecting the concentration of the active form of vitamin D3, the TCDD contributes to inhibition of the activity of fibroblasts. ${ }^{19}$ The key 
role in the pathomechanism of the TCDD activity is that of activation of the aryl hydrocarbon receptor (AhR), which one of its numerous consequences is disturbance of the synthesis of collagen fibers, ${ }^{\mathbf{1}, 20-22}$ which may result in disorders of their spatial structure. Jämsä et al. 2001 showed that altered transactivation domain of AhR is associated with a lower sensitivity of bone to TCDD in H/W rats, suggesting that AhR plays a role in modulating the effects of dioxins on bone. ${ }^{23}$ Also Herlin et al. 2013 found that exposure of adult mice to TCDD resulted in harder bone matrix, thinner cortical bone, mechanically weaker bones and most notably, increased trabecular bone volume fraction in $\mathrm{AhR}(+/+)$ mice. ${ }^{24}$ In vitro studies showed that osteoblasts $\operatorname{AhR}(-/-)$ mice showed reduction in mineralized bone nodule formation compared to cells from $\mathrm{AhR}(+/+)$ mice. It means that AhR is involved in bone development of a normal bone phenotype, and is crucial for manifestation of TCDD-induced bone alterations.

Despite a wide spectrum of the effects of different dioxins in humans and animals, there are some reports that assess the impact of TCDD on the mineralized tissues. Based on the outcome of experimental research, the TCDD has been shown to affect the integrity of the connective tissue, to inhibit the synthesis of collagen I and to induce oxidation stress which leads to an increase in the concentration of proinflammatory interleukines that activate osteoclastogenesis. ${ }^{2,21,22}$ Inhibition by a TCDD of the alkaline phosphatase activity and of some initiators of mineralization can result in formation of tissues of a low mineral level. ${ }^{17,22}$ TCDD activity has been found to negatively influence the biosynthesis of proteins in the liver, ${ }^{25,26}$ which affect the process of osteogenesis. ${ }^{27}$

Currently, attempts have been being undertaken to research methods to prevent the tissues and inhibit the negative effect of TCDD activity.

During the selection of pharmaceuticals that neutralize the impact of TCDD, which could react competitively with the AhR gene products. For instance, an inhibiting mechanism of molecular activity against $\mathrm{AhR}$ and the end products of dioxins biotransformation is usage of tocopherol. ${ }^{19,27-29}$ Induction of the inflammation by a dioxin is linked with generating free radicals and cyclooxygenase- 2 stimulation, the latter being responsible for production of prostanoids - inductors of inflammation. Therefore, dexamethazone (DEX) as a typical antiphilogistic substance and levamisol (LEV) as a immunomodulating medicament were applied. ${ }^{27}$ Besides, in order to inhibit the inflammation processes induced by prostanoides, non-steroid antiinflammatory medicaments are often used such as acetylsalicylic acid (ASA).

Tocopherol has an additional effect reducing the toxic impact of TCDD on an organism. It inhibits the production of free radicals and blocks the accessibility of the AhR and estrogen receptor for dioxins.

Impact of various external factors such as the discussed TCDD,$^{15,23}$ or drugs that prevent the development of skeletal diseases, affect the processes of bone remodeling. As the architecture of the bone tissue corresponds with its mechanical properties, examination of mechanical parameters enriches essentially the knowledge about the structure and functioning of bones ${ }^{30-32}$ as well as it enables to define the impact of the analyzed factors on the condition of bones.

Bone microarchitecture, density and strength consist endpoints of dioxin toxicity. However, less is known about effects on bone structure and mechanical properties. Taking into account all the aspects mentioned, the aim of the study was to analyze the TCDD effect on the mechanical properties and structure of the bone in female rats exposed to TCDD, and to estimate the influence of $\alpha$-tocopherol, levamisol, dexamethasone and acetylsalicylic acid in reduction of its toxic effect. All of the pharmaceutics used have distinct mechanism of action, moreover their activity is altering different points of TCCD toxicity pathway.

\section{Materials and methods}

\subsection{Materials}

The research material was composed of tibiae $(n=40)$ sampled from female rats representing the Buffalo strain (age 16 weeks, weight 130-150 g) bred at the Animal Experimental Station of the Pathomorphology Department, the Silesian Piasts Medical University in Wroclaw, Republic of Poland.

Female rats for the study had been randomized and divided into the six experimental and one control groups, each comprising six individuals. For intoxication the $1 \%$ solution of 2,3,7,8-tetrachlorodibenzo- $p$-dioxin (TCDD) (Greyhound Chromatography and Allied Chemicals) dissolved in dimethyl sulphoxide (DMSO) was used.

Each experimental group was treated with TCDD solution in day 0 of the experiment, in a single dose of a $5 \mu \mathrm{g} \mathrm{kg}{ }^{-1}$ b.w. i.m. groups were as follows:

(1). $\mathrm{K}$ - the control group, not exposed to the any chemical substance.

(2). TCDD - a group exposed to the effect of TCDD only administered intramuscularly into back limb muscles.

(3). TCDD + E - a group exposed to the TCDD and for 3 weeks treated with a solution of $\alpha$-tocopherol acetate in a dose of $30 \mathrm{mg} \mathrm{kg}{ }^{-1}$ b.w. per day hypodermically s.c.; $\alpha$-tocopherol acetate was used in oily solution (Hasco-Lek, Poland).

(4). TCDD + ASA - a group exposed to the TCDD and for 3 weeks treated with a suspension of the acetylsalicylic acid in a solution of starch at a dose of $50 \mathrm{mg} \mathrm{kg}^{-1} \mathrm{~b} . \mathrm{w}$. per day orally p.o.; ASA (Hasco-Lek, Poland).

(5). TCDD + ASA + E - a group exposed to the TCDD and for 3 weeks treated with a suspension of the acetylsalicylic acid in a solution of starch at a dose of $50 \mathrm{mg} \mathrm{kg}^{-1}$ b.w. per day orally p.o. and a solution of $\alpha$-tocopherol acetate at a dose of $30 \mathrm{mg}$ $\mathrm{kg}^{-1}$ b.w. per day hypodermically s.c.; $\alpha$-tocopherol acetate was used in oily solution (Hasco-Lek, Poland), ASA (Hasco-Lek, Poland).

(6). TCDD + DEX - a group exposed to the TCDD and for 3 weeks treated with dexamethazone at a dose of $100 \mu \mathrm{g} \mathrm{kg}{ }^{-1} \mathrm{~b} . \mathrm{w}$. per day intramuscularly i.m; $4 \mathrm{mg} \mathrm{mL}^{-1}$ solution for injections (PharmaSwiss).

(7). TCDD + LEV - a group exposed to the TCDD solution and for 3 weeks treated with levamisol at a dose of $2.5 \mathrm{mg} \mathrm{kg}^{-1} \mathrm{~b} . \mathrm{w}$. 
per day intramuscularly i.m.; $10 \%$ aqueous solution of levamisole (Vetoquinol Biowet, Gorzów Wielkopolski, Poland).

After 3 weeks of pharmaceutics administration, the animals were additionally observed for 7 weeks.

During the whole experiment the animals were kept in an air-conditioned room at the following physical parameters: (1) overpressure, (2) 15 air exchanges per hour, (3) air temperature ca. $22{ }^{\circ} \mathrm{C}$, (4) air moisture 55\%, (5) sunlight cycle 12/12 hours. The rats were kept in polystyrene cages with an access to food by "Labofeedh" and water. These conditions were to neutralize the disadvantageous effect of stress in the animals which would enhance the impact of dioxin activity.

After animals sacrificing, tibiae were taken for future analysis. General macroscopic analysis was performed just after bone removal. To avoid chemical treatment of material before mechanical tests, material was kept in $-20{ }^{\circ} \mathrm{C}$.

\subsection{Bone strength analysis}

The first step stage was to determine the mechanical properties of rat tibiae in a trial of three-point bending. ${ }^{23,31,32}$ This experimental study was conducted at the Department of Biomedical Engineering, Mechatronics and Theory of Mechanisms, Wroclaw University of Science and Technology.

To perform the three-point bending test and guarantee good stability of tibiae on the supports of the measuring setup, the nearer and farther bases of the bones had been induced in bushings (Fig. 1). The trials were carried out on a MTS Mini Bioniks 858 strength tester at a constant load speed rate of 2 $\mathrm{mm} \min ^{-1}$. The test was continued until the specimen failure.

During the study, changes in the force $F[\mathrm{~N}]$ as the function of displacement $d[\mathrm{~mm}]$ were recorded. Based on the collected data, the Young $E$ modulus and bending strength (BS) of tibiae to three-point bending were determined. The Young modulus, which characterizes resistance of material to deformations, was assessed based on the equation:

$$
E=\frac{F L^{3}}{48 f I_{x}}[\mathrm{MPa}]
$$

where $F$ - failure force, $L$ - testing span, $f$ - deflection, $I_{x}-$ moment of interia

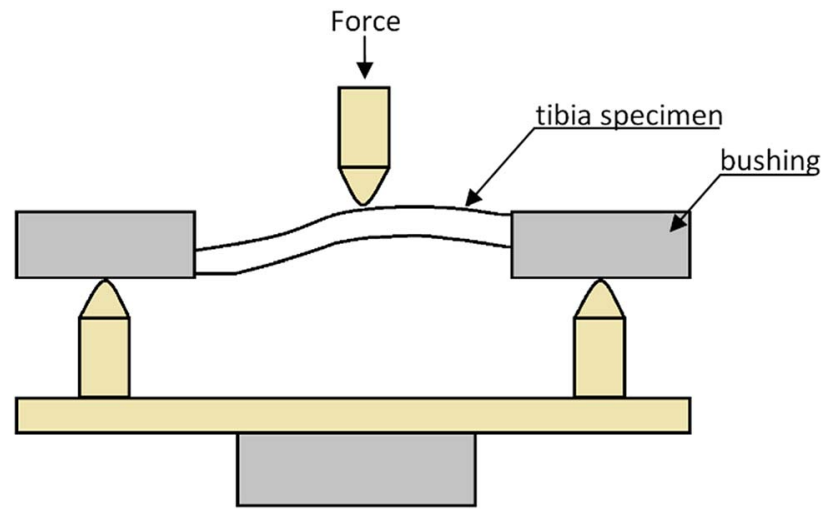

Fig. 1 Measuring setup for three-point bending of tibiae.
On account of the shape of tibiae and the issuing diversification of their cross-sections (Fig. 2a), after the mechanical investigation the bones were scanned with the use of a micro-CT (SkyScan 1172, Bruker®). The obtained 3D representations of the tibiae enabled to precisely determine the geometrical dimensions of the cross-sections where the bones had been fracture (Fig. 2b). The aim of this step was to find the moment of inertia $I_{x}$ necessary for the mechanical parameters to be defined. The acquired micro-CT pictures served also to determine the value of mineralization degree of the osseous tissue (BMD), which had been obtained based on the bone permeability to X-rays in relation to the permeability value for the density models dedicated to rat bones.

\subsection{Histological evaluation}

A further step of the research was a qualitative estimation of the tibiae from particular groups: the material sampled was subject to histological analysis. After fixation in $4 \%$ buffered formaldehyde solution, the bones were decalcified in a mixture of the formic acid and sodium citrate for 7 days, and subsequently after rinsing in tap water - the material was dehydrated in alcohol series and embedded in paraffin. Slices $5 \mu \mathrm{m}$ thick were stained by the routine manner with haematoxylin and eosin. Morphological analysis was performed using a Nicon Eclipse $80 \mathrm{i}$ microscope at normal and a fluorescence light with the application of a UV-2A Nikon filter.

\subsection{Analysis of mineral composition}

Mineralization of the bone samples was carried out with the employment of the wet method in a closed microwave system. To the scale of a homogeneous sample (from $0.1 \mathrm{~g}$ to $0.5 \mathrm{~g}$ ) 5 $\mathrm{cm}^{3}$ concentrated nitric acid (V) and $1 \mathrm{~cm}^{3}$ concentrated pure hydrogen peroxide were added, and next the samples were mineralized in the MARS 5 microwave system for sample preparation. The mineralizers were transferred quantitatively to measuring vessels of $10 \mathrm{~cm}^{3}$ cubic content with the use of redistilled water. Estimation of the contents of zinc, iron and magnesium was made by the absorption method, and the calcium content was assessed by the method of emission atom spectrometry in a flame of acetylene/air using a SpectraAA atom absorption spectrometer with a Varian AA240FS countershaft intended for usage in flame. Phosphorus was measured by the spectrophotometric method with the use of a Unicam UV300 spectrophotometer by ThermoSpectronic. The methods employed were confirmed through application of certified reference material (BCR-185R - Bovine Liver), the unreliability of measurements was assessed at $5 \%$.

\subsection{Statistics}

The results obtained underwent a statistical analysis. Due to the small number of samples in particular subgroups, it was impossible to verify the congruence of empirical distributions with the normal distribution, and therefore for a comparison of average values (medians) the non-parametric Kruskal-Wallis test was applied and a post-hoc test of repeated comparisons based on the Dunn test was performed. 


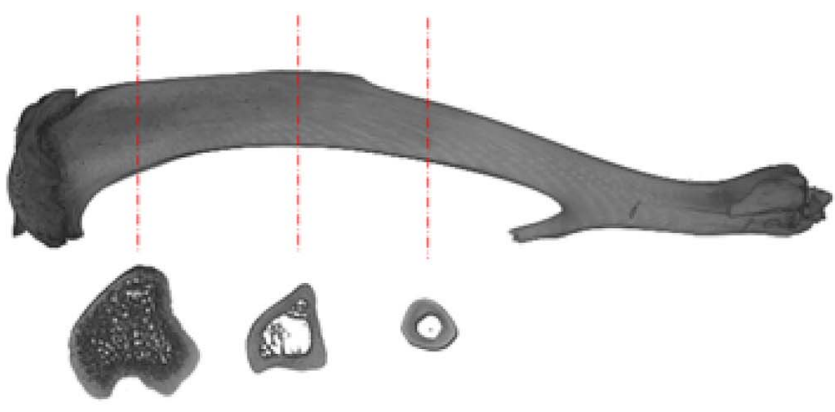

(a)

(b)

Fig. 2 (a) 3D-rendering and cross-sections of a rat tibiae before the mechanical investigation (control group) (b) cross-section of the bone used for $I_{x}$ calculation; the place of failure marked with an arrow.

\subsection{Live subject statement}

All materials in the present study was obtained according to all ethical guidelines and requirements applicable in such cases and was approved by the Local Ethics Council for Animal Experiments, Wroclaw, Republic of Poland (permission number: 83/2012). All procedures were carried out in accordance with appropriate guidelines and regulations of the Republic of Poland.

\section{Results}

\subsection{Mechanical investigations}

By exerting destructive influence on the metabolism of the bone and on the process of its formation, dioxins bring about changes both in the mechanical properties and structural characters of the tissue (Table 1 ). The experiments conducted have revealed that resistance of rat bones (Fig. 3) for the control group $\mathrm{K}$ is statistically significantly lower in comparison with the TCDD-exposed group treated with a single dose of dioxins $(p$ $<0.05$ ).

BS test showed that TCDD significantly increases bone rigidity in comparison to the control group. Other drugs do not induce increased rigidity and the results are not statistically significant (ASA, ASA + E and E). However, in DEX and LEV groups, potential reduction of the toxic effect of TCDD is observed, because obtained median value is similar to the results in $\mathrm{K}$ group.

In the case of the longitudinal elasticity modulus $E$, no statistically significant differences between the groups were found, although for the groups TCDD and ASA + E the values obtained exceeded that for the control by $46 \%$ and $49 \%$ respectively. Analysis of the degree of mineralization BMD of the compact bone (Fig. 4) shows an increase in this value for all research groups as related to the control. However, statistical significance at a level of $p<0.05$ was recorded only for groups DEX, E and TCCD.

BMD test showed that values of bone mass and density are significantly increased in TCDD, E, ASA + E and DEX groups in comparison to the $\mathrm{K}$ group. The median in ASA is insignificant when compared to the K group. This indicate that LEV and ASA have therapeutic effect and reduce the toxic influence of TCDD in bones from mechanical point of view.

Additionally, in order to assess the magnitude of relationships between the analyzed mechanical properties of all the examined bone samples, the Spearman rank correlation coefficient was used. A positive correlation between BMD and the Young modulus $\left(r_{\mathrm{S}}=+0.453 ; p<0.01\right)$ and a strong positive correlation between BMD and bending strength $\mathrm{BS}\left(r_{\mathrm{S}}=+0.328\right.$; $p<0.05)$ were detected.

\subsection{Histological study}

The study of the tibiae has focused on two major regions: epiphysis and diaphysis. Histological examination has revealed that dioxins cause intensification of osteoresorption processes, which is accompanied by enhanced synthesis of bone matrix, that leading to development of a disturbed structure of their diaphysis. As viewed from the side of periosteum, it is noticeable that there are no bone lamellae, which should have been

Table 1 Values of the bending strength, Young $E$ modulus and degree of bone mineralization BMD obtained for the research groups under analysis $^{a}$

\begin{tabular}{lllll}
\hline & Sample size $n$ & BS $[\mathrm{MPa}] \mathrm{Me}\left(Q_{1} ; Q_{3}\right)$ & $\mathrm{E}[\mathrm{GPa}] \mathrm{Me}\left(Q_{1} ; Q_{3}\right)$ & $\mathrm{BMD}\left[\mathrm{g} \mathrm{cm}{ }^{-3}\right] \mathrm{Me}\left(Q_{1} ; Q_{3}\right)$ \\
\hline K & 8 & $348(267 ; 427)$ & $22(17 ; 23)$ & $1.18(1.14 ; 1.24)$ \\
TCDD & 6 & $551(506 ; 600)^{*}$ & $41(35 ; 47)$ & $1.40(1.38 ; 1.42)^{*}$ \\
LEV & 5 & $421(334 ; 510)$ & $31(19 ; 36)$ & $1.25(1.17 ; 1.28)$ \\
E & 5 & $498(475 ; 582)$ & $34(22 ; 42)$ & $1.37(1.37 ; 1.45)^{*}$ \\
DEX & 6 & $403(285 ; 625)$ & $29(21 ; 32)$ & $1.42(1.35 ; 1.51)^{*}$ \\
ASA & 6 & $491(469 ; 508)$ & $26(22 ; 42)$ & $1.25(1.17 ; 1.28)$ \\
ASA + E & 4 & $484(435 ; 509)$ & $43(31 ; 48)$ & $1.39(1.31 ; 1.43)$
\end{tabular}

${ }^{a} n$ - sample size, Me - median, $Q_{1}$ - lower quartyl (25th percentyl), $Q_{3}$ - upper quartyl (75th percentyl), ${ }^{*} p<0.05$ as compared with the control. 


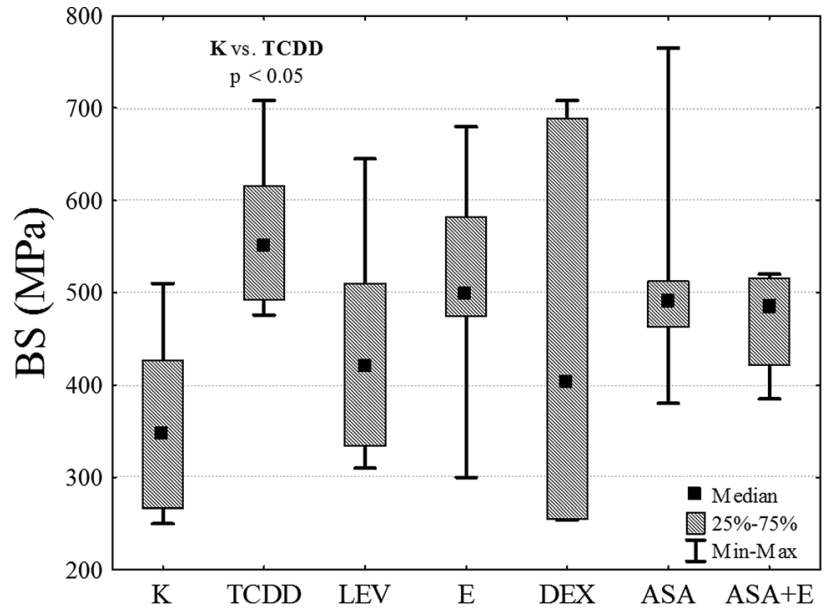

Fig. 3 A diagram of the obtained values of bending strength BS for particular research groups.

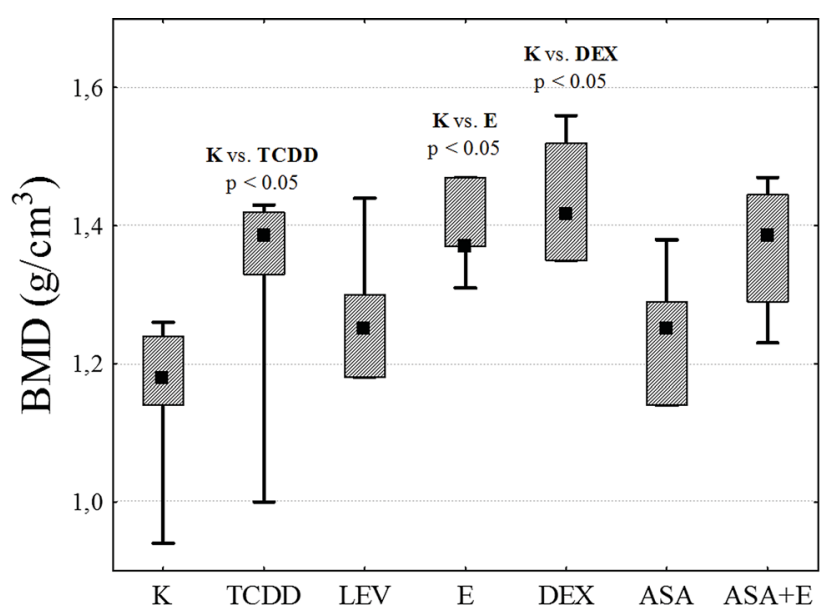

Fig. 4 A diagram of the obtained values of mineralization degree BMD for particular research groups.

deposited through apposition and covered by the periosteum. The marrow cavity is filled by an irregular callus. In the case of levamisol, the structure of the compact bone is party preserved, whereas the diaphysis show clear ossifications within the marrow. With vitamin $\mathrm{E}$ and dexamethasone applied, the bones are similar in structure to one another and to those of the control group. In the groups treated with ASA and ASA + E, the bone morphology displays changes within the articular cartilage in the epiphyseal region. Intensified divisions and enhanced synthesis of the cartilaginous matrix by chondrocytes within a bone diaphysis, accompanied by intensified proliferation of the marrow cells and osteoblasts, can be visible. Within the diaphysis, the surface bone layer is preserved, whereas within the marrow cavity spaces of accelerated ossification are detectable. In some groups alkali-absorptive "arrest lines" (Fig. 5, black arrow) are perceivable, which testify to inhibition of the bone matrix synthesis.

(Left picture - l; right picture - r) K group - 1 - periosteum, $\mathrm{r}$ endosteum, note regular layers of bone from periosteal and endosteal side; TCDD group - 1 - diaphysis center, $\mathrm{r}$ - diaphysis endosteum, note the presence of the irregular in shape collagen fibers; LEV group - 1 - diaphysis periosteum, $\mathrm{r}$ - diaphysis center, note the centers of ossification in the diaphysis center; $\mathrm{E}$ and DEX groups - diaphysis periosteum, note the presence of arrest lines (arrow) from periosteum; ASA group - 1 - diaphysis periosteum, $r$ - epiphysis, note the accelerate bone synthesis in the epiphysis; ASA + E group - 1 - diaphysis periosteum, $r$ epiphysis, arrest lines in diaphysis (arrow) and accelerate bone synthesis in epiphysis; mag. $200 \times$.

\subsection{Contents of elements}

In the analysis of mineral composition, the ratio illustrating the correctness in the architecture of the hydroxyl-apatite crystals was applied. In the ideal crystal the calcium to phosphorus ratio equals $1.67: 1$. Under in vivo conditions, depending on the animal species and the bone type, this ratio is usually lower; for the rat bones investigated in this study the ratio amounted to $1.03: 1$. TCDD exposure triggers a decrease of the calcium content in bones, which leads to diversion of the ratio to reach $0.9: 1$. Calcium is replaced by growing contents of zinc and iron. The situation of reverse ratio concerns groups ASA and ASA + E. In this case the increase in the zinc content can be associated with the presence of tocopherol as for these particular groups the highest content of this substance in bones has been recorded. The most substantial growth in the iron and zinc contents was found in the group treated with levamisol. This increase can be linked with enhanced storage of iron within the marrow, or with slowing down of hemopoiesis.

Iron in bones is a remnant after decomposition of haemoglobin and transport proteins. In group TCDD, the iron content has grown considerably, which may have resulted from intensified decomposition of erythrocytes or disturbed iron management. The remaining elements do not exhibit significant TCDD-induced deviations relative to the control group. In this case, all the compounds applied cause lowering of its level in bones and recovery. A drop in the magnesium content in bones at exposure to TCDD is confirmed by the protective influence of levamisol, whereas vitamin $\mathrm{E}$ and dexamethazone enhance this decrease.

Summing up, TCDD has a negative impact on the calcium content in bones by replacing this element. DEX displays the strongest protective effect, or its activity manifests itself through retaining of calcium in bones (Fig. 6), (Table 2).

\section{Discussion}

In spite of restrictive obligations issuing from the regulations of the Stockholm Convention that pertain to reduction of the emission to the environment of Persistent Organic Pollutants (POPs), including dioxins, the amount of contaminants emitted is still substantial. Released dioxins get incorporated into the food chains, subsequently bringing about an array of negative biological consequences., ${ }^{4,33-35}$

The processes of resorption and bone formation are closely linked with each other. Disturbance to the mutual induction processes, or inhibition of any of the bone synthesis stages, 

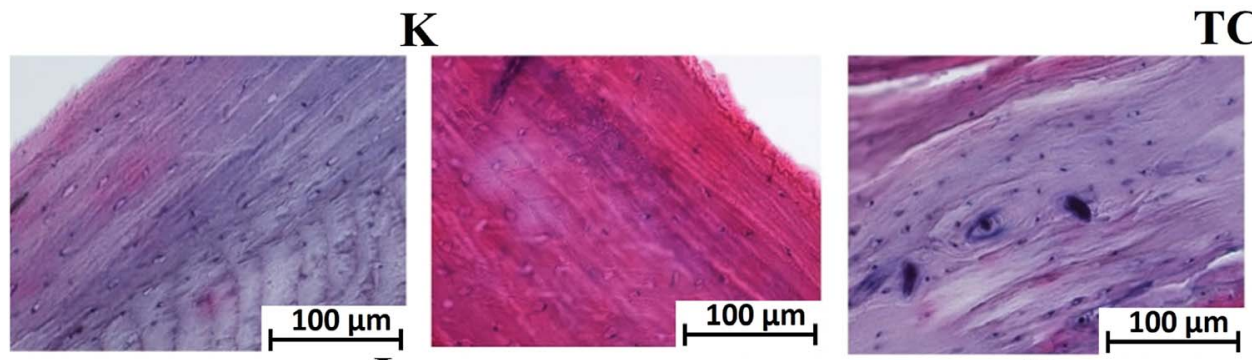

Lev

E

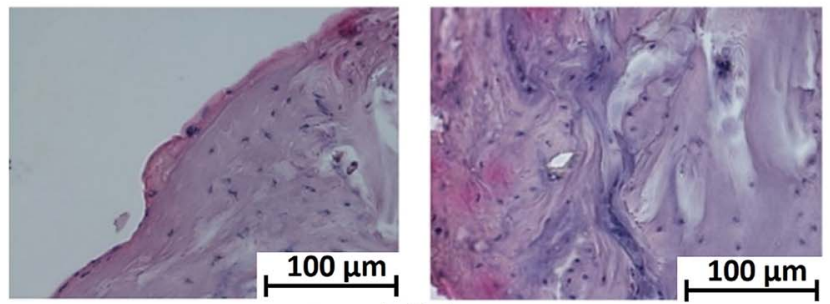

ASA
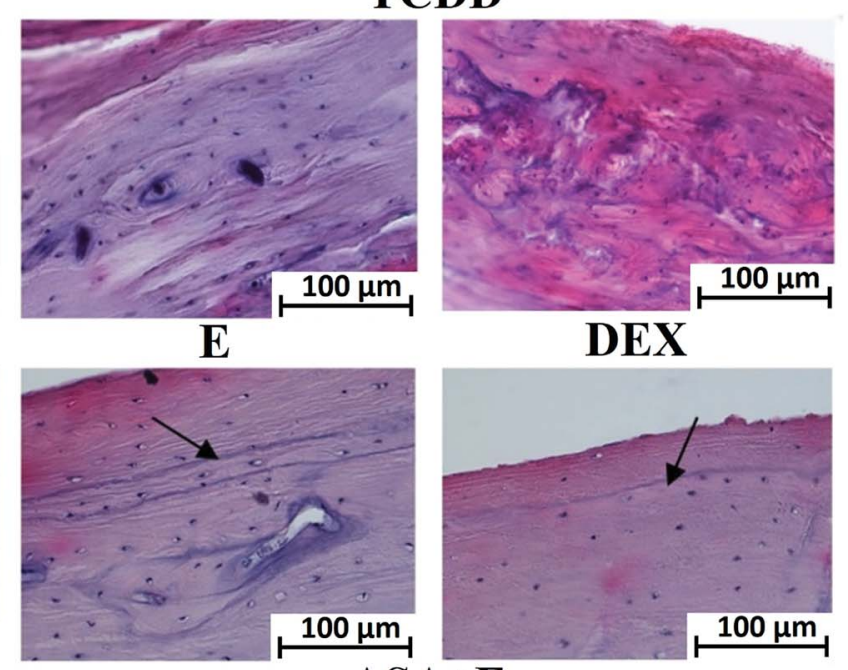

DEX
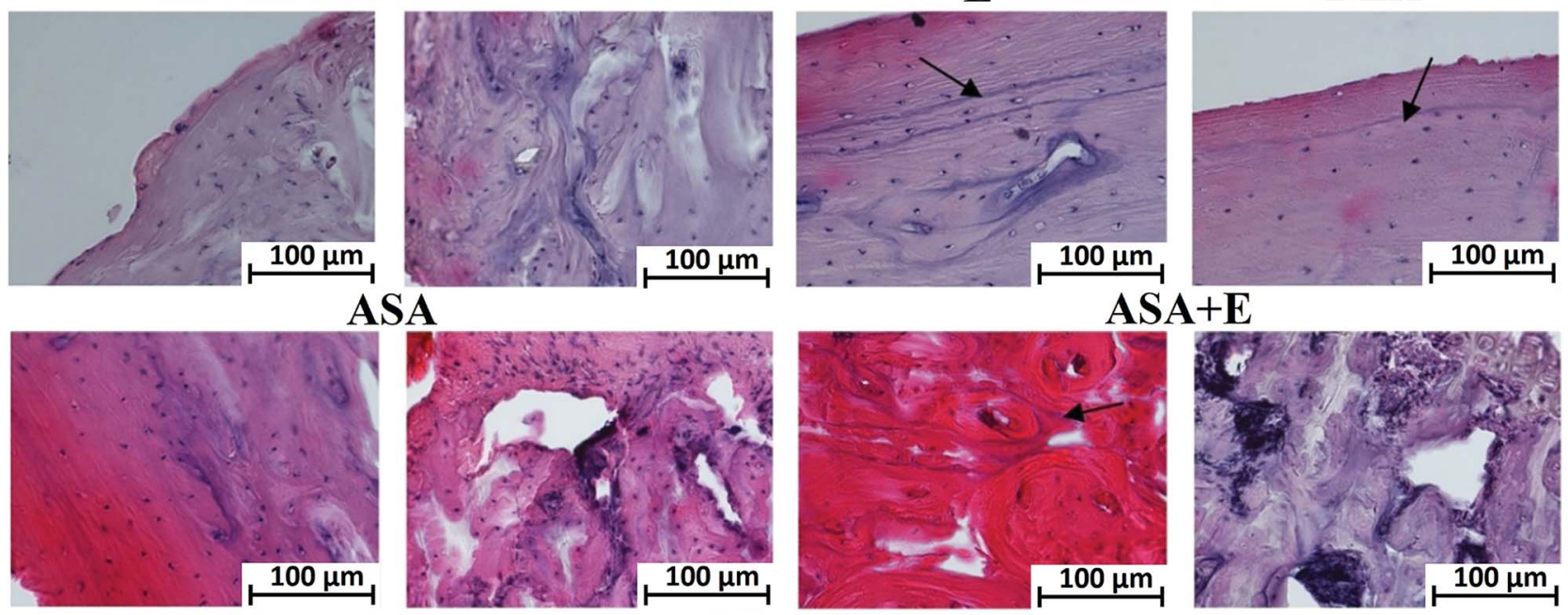

$\mathbf{A S A}+\mathbf{E}$

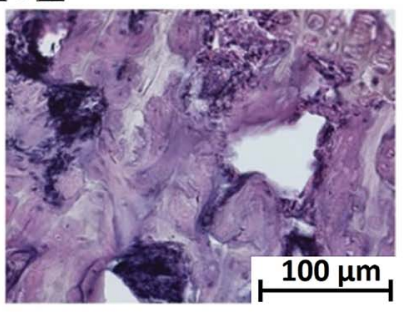

Fig. 5 Histological slides of rat tibiae from particular groups, stained with hematoxylin and eosin. (Left picture $-l$; right picture $-r$ ) $K$ group $-l-$ periosteum, $r$ - endosteum, note regular layers of bone from periosteal and endosteal side; TCDD group - l - diaphysis center, $r$ - diaphysis endosteum, note the presence of the irregular in shape collagen fibers; LEV group - 1 - diaphysis periosteum, $r$ - diaphysis center, note the centers of ossification in the diaphysis center; $E$ and DEX groups - diaphysis periosteum, note the presence of arrest lines (arrow) from periosteum; ASA group - I - diaphysis periosteum, $r$ - epiphysis, note the accelerate bone synthesis in the epiphysis; ASA + E group - I - diaphysis periosteum, $r$ - epiphysis, arrest lines in diaphysis (arrow) and accelerate bone synthesis in epiphysis; mag. 200x.

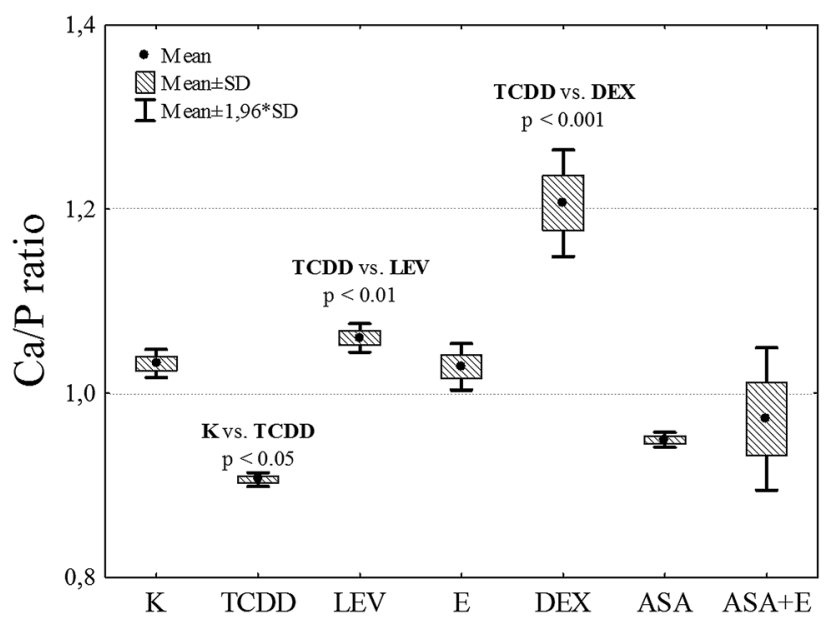

Fig. 6 Calcium to phosphorus ratio in the bones of the analyzed research groups. Scale bar represents standard deviation.

leads to disorders in the structure of the osseous tissue. This is reflected in its biomechanical properties and can result in developmental disorder. ${ }^{36}$ It is particularly essential in the case of foetuses and growing individuals. ${ }^{22}$ By affecting the metabolism of estrogens and vitamin D, the TCDD influences the expression of genes in osseous cells during their diversification. ${ }^{16}$ The hitherto made findings indicate that the direct impact of dioxins on bones concerns both the synthesis and resorption of bone. The impact of dioxins manifests itself in intensified osteoresorption, which is accompanied by enhanced osteogenesis. The new tissue that is a result of intense osteoresorption and rapid osteogenesis does not undergo full, correct mineralization and the calcium compounds being produced form amorphous aggregates, inaccessible for bioresorption, which make a bone stiff. On the other hand, however, biosynthesis of bones is inhibited at the side of periosteum, which means that dioxins interfere with the proliferation and diversification of osteoblasts which contribute to the development of a bone at the periosteum.

The study conducted shows that application of pharmaceuticals can neutralize the negative impact of dioxins on the osseous tissue. The analysis of mechanical properties has not revealed statistically significant differences between the control group and the groups treated with one of the analyzed medical agent. This means that the therapies employed weakened the TCDD effect on skeleton. In the groups treated with ASA and LEV, the obtained BMD values correspond with that of the healthy osseous tissue; this allows a conclusion that exposure to 
Table 2 Composition of elements in the research groups under analysis ${ }^{a}$

\begin{tabular}{|c|c|c|c|c|c|}
\hline & $\mathrm{Ca}\left[\mathrm{g} \mathrm{kg}^{-1}\right]$ & $\mathrm{P}\left[\mathrm{g} \mathrm{kg}^{-1}\right]$ & $\mathrm{Mg}\left[\mathrm{g} \mathrm{kg}^{-1}\right]$ & $\mathrm{Zn}\left[\mathrm{mg} \mathrm{kg}{ }^{-1}\right]$ & $\mathrm{Fe}\left[\mathrm{mg} \mathrm{kg} \mathrm{kg}^{-1}\right]$ \\
\hline & $\mathrm{M} \pm \mathrm{SD}$ & $\mathrm{M} \pm \mathrm{SD}$ & $\mathrm{M} \pm \mathrm{SD}$ & $\mathrm{M} \pm \mathrm{SD}$ & $\mathrm{M} \pm \mathrm{SD}$ \\
\hline TCDD & $195.54 \pm 3.07^{*}$ & $215.9 \pm 3.39 *$ & $4.30 \pm 0.01$ & $142.45 \pm 0.75^{*}$ & $57.92 \pm 1.17^{*}$ \\
\hline LEV & $235.62 \pm 3.84^{*^{+}}$ & $221.2 \pm 3.61^{*^{+}}$ & $4.74 \pm 0.03^{*^{+}}$ & $224.05 \pm 4.03^{*^{+}}$ & $43.99 \pm 0.79 *$ \\
\hline $\mathrm{E}$ & $235.28 \pm 3.69^{*^{+}}$ & $228.0 \pm 3.58^{*^{+}}$ & $4.10 \pm 0.03^{*^{+}}$ & $143.08 \pm 1.43^{*}$ & $18.05 \pm 0.17^{+}$ \\
\hline $\mathrm{ASA}+\mathrm{E}$ & $215.91 \pm 7.20^{+}$ & $224.3 \pm 6.02^{*^{+}}$ & $4.20 \pm 0.04^{*}$ & $139.06 \pm 1.03 *$ & $22.46 \pm 0.36^{+}$ \\
\hline
\end{tabular}

dioxins did not affect the processes of bone mineralization. However, statistically significant differences in BMD as compared with the control have been found for the groups treated with DEX and ASA + E. The increase in the BMD value acquired in effect of exposure to dioxins remains in accordance with the outcome of research pursued by other authors. ${ }^{15,23}$

Besides, the group treated with the acetylsalicylic acid have been noted to approximate to the control group in the mechanical properties and BMD of the bone. And thus, the ASA acid displays the highest potential for prevention of the negative effects of dioxins on skeleton.

The investigation proves, that the use of chosen pharmaceutics reduces negative influence of TCDD on bone.

Registered maximal destruction force was at the same level in the control group as well as in the other experimental groups, except TCDD group. However, the application of dexamethazone had negative feedback in mechanical tests. The use of TCDD influences only some of mechanical properties of tested bone. In case of changes in bone rigidity parameter, we didn't observed any significant changes between control and TCDD groups. Similar results were presented by Herlin et al. 2013; Finnila et al. 2010, ${ }^{15,24}$ where TCDD application didn't change rigidity of the bones. In the case of maximal destruction force, Finnila et al. received significant differences between control and TCDD groups, whereas Herlin et al. showed significant changes in bone properties in males mice only. In spite of the fact, in these experiments the dose of TCDD was higher than in our research.

Lind et al. (2009) ${ }^{37}$ have demonstrated that exposure of adult rats to dioxins triggers changes in the matrix composition, which are typical of mature bone (of increased mineralization). This means that the compounds discussed act as inhibitors of the natural processes of the bone remodeling, which results in slowing down of the mineralization of bones being developed and in inhibition of the processes of osteocytic osteolysis in older animals, that leading to hypermineralization.

The analysis of morphology and mineral composition shows an increased ratio of calcium to phosphorus in groups where dexamethazone or levamisol was applied, which signifies inhibition of the process of recruitment of osteoclasts. DEX and LEV by arrest of osteoclastogenesis, therefore maintain calcium in bones by inhibition of resorption processes. The TCDD alone clearly reduces the calcium content, but this effect is strongly limited by tocopherol. Tocopherol combined with ASA, or ASA alone, insignificantly inhibits the negative impact of dioxins on the osseous tissue.

Interfering with the estrogen management, TCDD contributes to decreased depositing of calcium in mineralized tissues, and - by intensifying the concentration of corticosterone stimulates decomposition of collagen fibers. The activity of dexamethazone and vitamin E noticeably inhibits the negative effect of dioxins on the osseous tissue, dexamethazone and levamisol enhancing the processes of mineralization but inhibiting the processes of osteolysis, which is associated with their anti-inflammatory influence. It is interesting that the effect of dexamethazone as a protective medicament is individual-dependent in the osseous tissue. The examination of the biomechanical properties and analyses of BMD, element composition and osseous tissue structure illustrate the widest scatter of results as compared with the remaining groups.

Moreover, an important role in the pathomechanism of the TCDD activity is that of activation of the AhR. One of its numerous consequences is disturbance of the synthesis of collagen fibers, which may result in disorders to the spatial structure of the osseous tissue.

The acetylsalicylic acid along with vitamin E, as inhibitors of the AhR, display an additional activity protecting the cartilaginous cells present in joints via enhancement of chondrogenesis. These observations are congruent with findings by other researchers. ${ }^{16,18,23,38}$

Analysis of the obtained morphological and the microindentation results achieved by Herlin et al. 2013 (ref. 24) and Finnila et al. $2010,{ }^{15}$ allow us to conclude that the bone strength subjected to TCDD has a major effect on the decrease in the mineralization value and geometric variability of the bone, but not on the mechanical strength of individual bone structures.

This means that the destructive effect of dioxins on the metabolism of the bone and the process of bone formation does not involve only local impact (in the bone tissue cells) but affects the entire system of an organism, the result of which is a decline of the calcium level in blood both in the mother and offspring as a possible consequence of the proinflammatory activity of dioxins. ${ }^{27}$ Therefore, the TCDD and its derivates are 
particularly dangerous to young individuals - neonates, growing juveniles, and even ones in their mother's womb (mammals) during the initial stages of bone formation.

The investigations confirmed the thesis that the TCDD affects the rat bone by modulation of the mechanical resistance, Young modulus and bending strength. The applied pharmaceuticals may neutralize or reduce the impact of the TCDD on the bone tissue.

\section{Conclusions}

TCDD impacts the bones mineralization level and therefore activates adaptation processes which lead to severe changes in bone mechanical and structural properties.

Taking into account all performed tests, it has been shown that all pharmacological agents used, limit the negative impact of TCDD on the bone.

All used anti-inflammatory and immunomodulating drugs prevent this phenomenon in different ways, by inhibition or reduction of the inflammatory response within the tissues after TCDD application. The levamisol, tocopherol and dexamethazone reduce bone demineralization by inhibition of osteoclasts recrutation, whereas acetylsalicylic acid increases bone matrix synthesis but not it's mineralization and inhibits propagation of inflammatory response.

\section{Conflicts of interest}

The authors declare that there is no conflict of interests regarding the publication of this paper.

\section{Acknowledgements}

This work was supported by a grant 28/Pbmn from Wroclaw Medical University as well as by Wroclaw Centre of Biotechnology and The Leading National Research Centre (KNOW) programme, for years 2014-2018. Moreover, financial support from the National Science Centre over the course of the realization of the projects 'Preparation and characterization of nanoapatites doped with rare earth ions and their biocomposites' (no. UMO-2012/05/E/ST5/03904) and 'Preparation and characterisation of biocomposites based on nanoapatites for theranostic' (no. UMO-2015/19/B/ST5/01330) are gratefully acknowledged. The authors would like to thank Prof. PhD Ireneusz Calkosinski (1951-2017) for inspiration and his helpful advice, help in organization and welfare of the animals.

\section{References}

1 M. Dobrzyński, J. Bazan, A. Gamian, J. Rosińczuk-Tonderys, O. Parulska and I. Całkosiński, Annu. Set. Environ. Prot., 2014, 16, 300-322.

2 I. Całkosiński, J. Rosińczuk-Tonderys, M. Szopa, M. Dobrzyński and A. Gamian, Postepy Hig. Med. Dosw. (Online), 2011, 65, 143-157.

3 M. Dobrzyński, The influence of tocopherol and acetylsalicylic acid on tooth organ structure in offspring of rat dams undergoing 2,3,7,8-tetrachlorodibenzo- $p$-dioxin (TCDD), Doctoral Thesis, Wroclaw Medical University, 2012. 4 M. Dobrzyński, I. Całkosiński, I. Przywitowska, J. KobierskaBrzoza, A. Czajczyńska-Waszkiewicz, E. Sołtan and O. Parulska, Pol. J. Environ. Stud., 2009, 18, 319-323.

5 World Health Organization-IARC, IARC MonographsMonographs available in PDF format, http:// monographs.iarc.fr/ENG/Monographs/vol69/index.php, (accessed 17 April 2018).

6 F. P. Guengerich, J. Biol. Chem., 1991, 266, 10019-10022.

7 D. Palut, G. Kostka and P. Strucinski, Rocz. Panstw. Zakl. Hig., 2002, 53, 321-332.

8 M. Naruse, Y. Ishihara, S. Miyagawa-Tomita, A. Koyama and H. Hagiwara, Endocrinology, 2002, 143, 3575-3581.

9 M. Dobrzyński, U. Kaczmarek, P. Kuropka, P. Reichert, K. Grzech-Leśniak and I. Całkosiński, Pol. J. Vet. Sci., 2017, 20, 769-778.

10 K. Gostomska-Pampuch, A. Ostrowska, P. Kuropka, M. Dobrzyński, P. Ziółkowski, A. Kowalczyk, E. Łukaszewicz, A. Gamian and I. Całkosiński, Histochem. Cell Biol., 2017, 147, 523-536.

11 J. Rosińczuk, R. Dymarek and I. Całkosiński, BioMed Res. Int., 2015, 2015, 1-13.

12 I. Calkosinski, J. Rosinczuk-Tonderys, M. Dobrzynski, L. Palka and J. Bazan, Adv. Exp. Med. Biol., 2013, 788, 283292.

13 I. Całkosiński, J. Rosińczuk-Tonderys, A. BronowickaSzydełko, K. Dzierzba, J. Bazan, M. Dobrzyński, J. Majda and A. Gamian, Toxicol. Ind. Health, 2015, 31, 510-522.

14 M. Dobrzyński, M. Korczyński, K. Herman and I. Całkosiński, Przem. Chem., 2016, 1, 155-158.

15 M. A. Finnila, P. Zioupos, M. Herlin, H. M. Miettinen, U. Simanainen, H. Hakansson, J. Tuukkanen, M. Viluksela and T. Jamsa, J. Biomech., 2010, 43, 1097-1103.

16 J. F. Gierthy, J. B. Silkworth, M. Tassinari, G. S. Stein and J. B. Lian, J. Cell. Biochem., 1994, 54, 231-238.

17 A. Kiukkonen, M. Viluksela, C. Sahlberg, S. Alaluusua, J. T. Tuomisto, J. Tuomisto and P. L. Lukinmaa, Toxicol. Sci., 2002, 69, 482-489.

18 M. Korkalainen, E. Kallio, A. Olkku, K. Nelo, J. Ilvesaro, J. Tuukkanen, A. Mahonen and M. Viluksela, Bone, 2009, 44, 1134-1142.

19 N. Nishimura, H. Nishimura, T. Ito, C. Miyata, K. Izumi, H. Fujimaki and F. Matsumura, Toxicol. Appl. Pharmacol., 2009, 236, 301-309.

20 C. H. Andreasen, K. L. Stender-Petersen, M. S. Mogensen, S. S. Torekov, L. Wegner, G. Andersen, A. L. Nielsen, A. Albrechtsen, K. Borch-Johnsen, S. S. Rasmussen, J. O. Clausen, A. Sandbæk, T. Lauritzen, L. Hansen, T. Jørgensen, O. Pedersen and T. Hansen, Diabetes, 2008, 57, 95-101.

21 E. A. Andreasen, L. K. Mathew, C. V. Löhr, R. Hasson and R. L. Tanguay, Toxicol. Sci., 2007, 95, 215-226.

22 S. U. Singh, R. F. Casper, P. C. Fritz, B. Sukhu, B. Ganss, B. Girard, J. F. Savouret and H. C. Tenenbaum, J. Endocrinol., 2000, 167, 183-195. 
23 T. Jämsä, M. Viluksela, J. Tuomisto, J. Tuomisto and T. Juha, J. Bone Miner. Res., 2001, 16, 1812-1820.

24 M. Herlin, M. A. J. Finnilä, P. Zioupos, A. Aula, J. Risteli, H. M. Miettinen, T. Jämsä, J. Tuukkanen, M. Korkalainen, H. Håkansson and M. Viluksela, Toxicol. Appl. Pharmacol., 2013, 273, 219-226.

25 I. Całkosiński, J. Rosińczuk-Tonderys, J. Bazan, K. Dzierzba, M. Całkosińska, J. Majda, M. Dobrzyński and A. BronowickaSzydełko, Inflammation, 2013, 36, 387-404.

26 I. Całkosiński, J. Rosińczuk-Tonderys, A. BronowickaSzydełko, K. Dzierzba, J. Bazan, M. Dobrzyński, J. Majda and A. Gamian, Toxicol. Ind. Health, 2015, 31, 510-522.

27 I. Całkosiński, The influence of tocopherol on diagnostic indexes of inflammatory reaction in rats undergoing dioxin exposition, Habilitation Thesis, Wroclaw Medical University, 2008.

28 E. Kloser, S. Böhmdorfer, L. Brecker, H. Kählig, T. Netscher, K. Mereiter and T. Rosenau, Eur. J. Org. Chem., 2011, 13, 2450-2457.

29 C. J. MacDonald, H. P. Ciolino and G. C. Yeh, Cancer Res., 2004, 64, 429-434.
30 A. Nikodem, S. Dragan, S. Kołacz and Z. Dobrzanski, Pol. J. Vet. Sci., 2012, 15, 275-283.

31 B. Nowak, A. Matuszewska, J. Filipiak, A. Nikodem, A. Merwid-Lad, M. Pieśniewska, L. Fereniec-Gołebiewska, J. Kwiatkowska and A. Szelag, Adv. Med. Sci., 2016, 61, 85-89. 32 C. Pezowicz and M. Glowacki, Acta Bioeng. Biomech., 2012, 14, 53-60.

33 I. Całkosiński, J. Majda, G. Terlecki, K. Gostomska-Pampuch and A. Gamian, Adv. Exp. Med. Biol., 2013, 283-292.

34 H. Fiedler, Chemosphere, 2007, 67, S96-S108.

35 P. Struciński, J. Piskorska-Pliszczyńska, K. Góralczyk, M. Warenik-Bany, S. Maszewski, K. Czaja and J. K. Ludwicki, Rocz. Panstw. Zakl. Hig., 2011, 62, 3-17.

36 M. Tomanik, A. Nikodem and J. Filipiak, J. Mech. Behav. Biomed. Mater., 2016, 64, 86-93.

37 P. M. Lind, C. Wejheden, R. Lundberg, P. Alvarez-Lloret, S. A. B. Hermsen, A. B. Rodriguez-Navarro, S. Larsson and A. Rannug, Chemosphere, 2009, 75, 680-684.

38 D. Carpi, M. Korkalainen, L. Airoldi, R. Fanelli, H. Hakansson, V. Muhonen, J. Tuukkanen, M. Viluksela and R. Pastorelli, Toxicol. Sci., 2009, 108, 330-343. 